\title{
EDITORIAL AND COMMENT \\ Moving the Needle on Gender Equity: a Call for Personal and Organizational Action
}

\author{
Carol K. Bates, $M D^{7}$ and Amy S. Gottlieb, $M D^{2}$ \\ 'Harvard Medical School, Boston, MA, USA; 2University of Massachusetts Medical School - Baystate, Springfield, MA, USA.
}

$\mathrm{J}$ Gen Intern Med 34(3):329-30

DOI: $10.1007 / \mathrm{s} 11606-018-4798-7$

๑) Society of General Internal Medicine 2019

I $\mathrm{n}$ this issue of JGIM, Carr and colleagues remind us that our medical community has a way to go to close the gender gap that has been identified (and experienced) among our workforce for generations. ${ }^{1}$ Their report highlights key findings of all grantees of the Research Partnership on Women in Science Careers, a National Institutes of Health (NIH) funding vehicle to investigate factors impeding the professional advancement of women in medicine and science. ${ }^{2,3}$ The conclusions and recommendations are particularly compelling since these authors have generated most of the academic medical literature on this subject in the last five years.

Given that half the members of the Society of General Internal Medicine (SGIM) are women, it is conceivable that many of us believe our own field has achieved gender equity. We realize that many JGIM readers and authors are deeply committed to addressing disparities in the workplace and are motivated to model best practices for themselves and their home institutions and for medicine writ large. Since culture change requires leadership alignment, organization-wide conversations, and supportive infrastructure that impacts individual behavior, we offer the following suggestions to ensure we continue to move the needle forward.

Personal actions:

1. Recognize that we all carry implicit biases. Because these biases are unconscious, developing awareness is a necessary first step to addressing them. Readers who have not already taken an implicit association test should do so at https://implicit.harvard.edu/implicit/. We suggest the test on associations with women and science, but there are many possible options.

2. Be mindful of gender stereotyping language. A recent analysis of language in military evaluations found stark differences between languages describing the performance of men and women. ${ }^{4}$ Consider scanning and correcting performance evaluations and letters of reference for gendered adjectives, for example, describing women as compassionate and enthusiastic and men as

Published online January 2, 2019 analytical and competent. Additionally, observe and acknowledge the different ways men and women physicians are addressed in the workplace. Women are less often referred to by their professional titles than men. ${ }^{5}$ Allyship of male colleagues in this effort is critical to promoting gender-fair language and extinguishing linguistic asymmetries that diminish women's professional contributions and accomplishments.

3. Strongly consider using your influence to expand the number of women in prominent roles: Embrace sponsorship. Corporate America recognized a decade ago the impact that sponsorship — as opposed to mentorship - has on professional upward mobility and that men tend to have more of it. ${ }^{6}$ The same is true of academic medicine. ${ }^{7}$ By definition, a sponsor has significant organizational influence and a willingness to leverage his or her seat at the decision-making table to provide professional opportunities for others. Fortunately, successful sponsorship paradigms to support the career advancement of women have emerged in academic medicine and are ready for replication by those who seek to get more women into senior leadership. ${ }^{6,8}$

Organizational influence:

1. Explore whether or not leaders and members of search committees in your home institution are educated about implicit bias and charged with developing a broad list of candidates and specific job competencies when searching for deans, CEOs, department chairs, and division chiefs. View the Association of American Medical College's video "What You Don't Know: The Science of Unconscious Bias and What to Do About it in the Search and Recruitment Process" and lobby your organization to require all search committee members to do the same before reviewing dossiers and interviewing candidates. ${ }^{9}$ Additionally, consider implementing regular educational workshops like Breaking the Bias Habit, which teach specific strategies to mitigate unconscious bias and have been shown to increase the number of women hired. ${ }^{10}$

2. Ask whether your institution performs ongoing salary reviews and benchmarking to reflect objective, marketbased ranges. If so, encourage transparency around these benchmarks and persuade leadership to assess how compensation ranges compare, based on gender, for 
similar work and similar roles. It is especially important for men to raise this question-we should all be paid fairly.

3. Examine your institution's record of rewarding academic promotion and high-profile awards and lectures. Bring gender disparities to the attention of leadership and offer potential solutions to make the process of reward transparent and equitable.

4. Encourage regular tracking and leadership accountability for gender-equity metrics in recruitment, retention, compensation, and promotion. Organizations can only manage what they measure.

\section{WHAT CAN SGIM DO?}

Dr. Suzanne Fletcher served as the only female president in the first ten years of the Society, but $40 \%$ of SGIM elections have yielded female presidents in the last twenty years. While there are no national data on the percent of women who lead professional organizations, we do know that women represented only $12 \%$ of chairs of internal medicine in 2013 and only $16 \%$ of deans in 2015 . In this regard, SGIM is leading the way with near parity in leadership.

By contrast, considerable disparities still exist in SGIM career achievement awards. Only four of 33 recipients of the Robert J. Glaser award, five of 18 recipients of the John M. Eisenberg National Award for Career Achievement in Research, and five of 23 of the Career Achievement Award in Medical Education awards have been women. While we would not recommend setting fixed gender targets for awards, we do suggest that award committees make concerted efforts to ensure that women are represented in the pool of candidates. Constructing processes for increasing female nominees could include outreach to Committee and Interest Group Chairs seeking qualified female candidates, creation and dissemination of nomination templates, and annual meeting workshops on how to nominate led by past Award Committee Chairs.

Lastly, SGIM frequently issues statements and takes positions on a host of health policy issues that affect our patients and members nationally. Similarly, the Society should assume a public stance about workforce disparities and include research about gender equity on its list of recommended national funding priorities. The NIH has historically sponsored critical research on women's careers; however, that funding mechanism has ended.
Carr and colleagues have demonstrated that academic medicine continues to need intentional, coordinated efforts, as well as further study of such endeavors, to build a professional culture in which gender equity can flourish. Our individual and collective voices in advocating for all aspects of this culture change are essential if we as a field are to benefit from the talents of our entire workforce.

Acknowledgements: Dr. Bates is past Chair and Dr. Gottlieb is a current member of the Steering Committee, Group on Women in Medicine and Science, Association of American Medical Colleges.

Corresponding Author: Carol K. Bates, MD; Harvard Medical School, Boston, MA, USA (e-mail: carol_bates@hms.harvard.edu).

Compliance with Ethical Standards:

Conflict of Interest: The authors declare that they do not have a conflict of interest.

Publisher's Note: Springer Nature remains neutral with regard to jurisdictional claims in published maps and institutional affiliations.

\section{REFERENCES}

1. Carr PL, Helitzer D, Freund $\mathbf{K}$, et al. A summary report from the research partnership on women in science careers. JGIM. 2018. https:// doi.org/10.1007/s11606-018-4547-y.

2. Morgan AU, Chaiyachati KH, Weissman GE, Liao JM. Eliminated gender-based bias in academic medicine: more than naming the elephant in the room. JGIM. 2018;33:966-968.

3. Pololi LH, Civian JT, Brennan RT et al. Experiencing the culture of academic medicine: gender matters, a national study. JGIM. 2013;28:201-7.

4. Smith DG, Rosenstein JE, Nikolov MC. The different words we use to describe male and female leaders. Harvard Business Review May 25, 2018.

5. Files JA, Mayer AP, Ko MG et al. Speaker introductions at internal medicine grand rounds: forms of address reveal gender bias. J Womens Health 2017;26:413-19

6. Gottlieb AS, Travis EL. Rationale and models for career advancement sponsorship in academic medicine: the time is here; the time is now. Academic Medicine. 2018:93:1620-1623

7. Patton EW, Griffith KA, Jones RD, Stewart A, Ubel PA, Jagsi R. Differences in mentor-mentee sponsorship in male vs female recipients of national institutes of health grants. JAMA Intern Med. 2017;177:580582.

8. Roy B, Gottlieb AS. The career advising program: a strategy to achieve gender equity in academic medicine. J Gen Intern Med. 2017;32:601602.

9. What You Don't Know: The Science of Unconscious Bias and What To Do About it in the Search and Recruitment Process. https://www.aamc.org/ members/leadership/catalog/178420/unconscious_bias.html. Accessed $11 / 20 / 18$

10. Carnes M, Devine PG, Baier Manwell L, et al. The effect of an intervention to break the gender bias habit for faculty at one institution: a cluster randomized, controlled trial. Acad Med. 2015;90(2):221-230. 